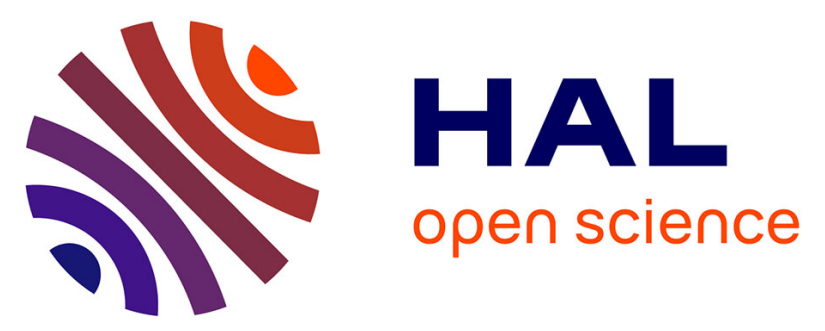

\title{
Effect of substitution on the solid-state fluorescence properties of styrylbenzoxazole derivatives with terminal dicyanomethylene group
}

\author{
Emma Bremond, Nadine Leygue, Thomas Jaouhari, Nathalie \\ Saffon-merceron, Arnaud Erriguible, Suzanne Fery-Forgues
}

\section{To cite this version:}

Emma Bremond, Nadine Leygue, Thomas Jaouhari, Nathalie Saffon-merceron, Arnaud Erriguible, et al. Effect of substitution on the solid-state fluorescence properties of styrylbenzoxazole derivatives with terminal dicyanomethylene group. Journal of Photochemistry and Photobiology A: Chemistry, 2021, 404, 112857 (9 p.). 10.1016/j.jphotochem.2020.112857 . hal-02973036

\author{
HAL Id: hal-02973036 \\ https://hal.science/hal-02973036
}

Submitted on 19 Oct 2021

HAL is a multi-disciplinary open access archive for the deposit and dissemination of scientific research documents, whether they are published or not. The documents may come from teaching and research institutions in France or abroad, or from public or private research centers.
L'archive ouverte pluridisciplinaire HAL, est destinée au dépôt et à la diffusion de documents scientifiques de niveau recherche, publiés ou non, émanant des établissements d'enseignement et de recherche français ou étrangers, des laboratoires publics ou privés. 


\title{
Effect of substitution on the solid-state fluorescence properties of styrylbenzoxazole derivatives with terminal dicyanomethylene group
}

\author{
Emma Bremond $^{\mathrm{a}}$, Nadine Leygue ${ }^{\mathrm{a}}$, Thomas Jaouhari ${ }^{\mathrm{b}}$, Nathalie Saffon-Merceron ${ }^{\mathrm{c}}$, \\ Arnaud Erriguible ${ }^{\mathrm{b}, \mathrm{d}}$, Suzanne Fery-Forgues ${ }^{\mathrm{a}, *}$ \\ ${ }^{a}$ SPCMIB, CNRS UMR 5068, Université de Toulouse III Paul Sabatier, 118 route de Narbonne, Toulouse, \\ 31062, France \\ ${ }^{b}$ CNRS, Université de Bordeaux, Bordeaux INP, ICMCB, UMR 5026, F-33600, Pessac cedex, France \\ ${ }^{c}$ Service commun RX, Institut de Chimie de Toulouse, ICT- FR2599, Université de Toulouse III Paul Sabatier, \\ 31062 Toulouse cedex 9, France. \\ ${ }^{d}$ Bordeaux INP, University of Bordeaux, CNRS, Arts et Métiers Institute of Technology, INRAE, I2M Bordeaux, \\ F-33600 Talence, France.
}

*Corresponding author. E-mail: $\underline{\text { sff@chimie.ups-tlse.fr }}$

Keywords:

Aggregation induced emission (AIE)

Solid state luminescence enhancement (SLE)

Photoluminescence

Benzoxazole

\begin{abstract}
Three styrylbenzoxazole derivatives with terminal dicyanomethylene group were studied in order to understand how minor modifications brought to the benzoxazole ring influence the photoluminescence properties. The three compounds were weakly fluorescent in organic solution because of molecular motions around the styryl single bonds. The unsubstituted (1) and methoxy (2) derivatives showed clear solid-state luminescence enhancement (SLE) properties. Distinct emission characteristics were attributed to the formation of amorphous and crystalline particles owing to scanning electron microscopy. These two compounds were also strongly luminescent as microcrystalline powders. Compound 1 that crystallized as slip stacks was a better emitter than the methoxy derivative $\mathbf{2}$, in which intermolecular interactions are more numerous, according to X-ray diffraction analysis. In contrast, compound $\mathbf{3}$ was virtually not emissive, confirming that in this series of dyes the presence of the hydroxy group is detrimental to PL emission, as rarely observed among SLE-active fluorophores.
\end{abstract}

\section{Introduction}

Over the last two decades, materials based on pure fluorescent organic dyes have received considerable attention because of potential applications in the fields of sensing, optics and optoelectronics. However, their rational design is challenging because the photoluminescence (PL) properties, which strongly depend on molecular conformation and interactions in the solid state, are hardly predictable [1-4]. Systematic studies are required to provide empirical information and improve the development of efficient materials.

Most of 2-phenylbenzoxazole (PBO) derivatives have proven to be excellent solid-state emitters that combine robustness and outstanding PL properties, owing to very favourable molecular arrangements [5]. Enlarging the electron conjugated system to access the family of styrylbenzoxazole dyes, while introducing some degrees of rotational freedom, is one of the ways to confer the molecules with solid-state luminescence enhancement (SLE) properties [6], meaning that molecules are much more emissive in the various solid states (crystals, powders, nanoparticles, as well as frozen or solid solutions) than in liquid solutions, due to intra- and intermolecular contributions. It should be noted that the popular aggregation-induced emission (AIE) term [7, 8], which refers to intermolecular 
mechanisms generated by the formation of aggregates, is included into the SLE term. Recently, we managed to make SLE properties appear by introducing the small dicyanovinyl group, a classical electron acceptor [9]. Remarkably, the PL properties were also reversibly modified by grinding and solvent fuming or heating, and this was the first example of mechanofluorochromic (MFC) behaviour in this series of compounds. The following work was focussed on molecules where a dicyanomethylene group has been integrated into a rigid and bulky dimethylcyclohexene moiety. The two double bonds of the styryl group allow the excitation and emission spectra to be shifted to the red with respect to the previously studied dicyanovinyl-PBO [9], while giving some flexibility to the molecule. Compound 1 (Fig. 1) was introduced by Yadav et al. who studied its fluorescence properties in solution and performed DFT calculations [10]. It was reported to exhibit enhanced emission in the solid state, but these properties have not been quantified. In compound 2, a methoxy group was introduced in the 5-position of PBO to slightly strengthen the electron donor character of the benzoxazole unit, and above all because this strongly structuring group may influence the PL properties [11-14]. A comparison was also made with the hydroxy analogue (3). After a brief study in solution, the spectroscopic properties of the three compounds were thoroughly studied in the aggregated and solid states, and tentatively connected with crystallographic data.

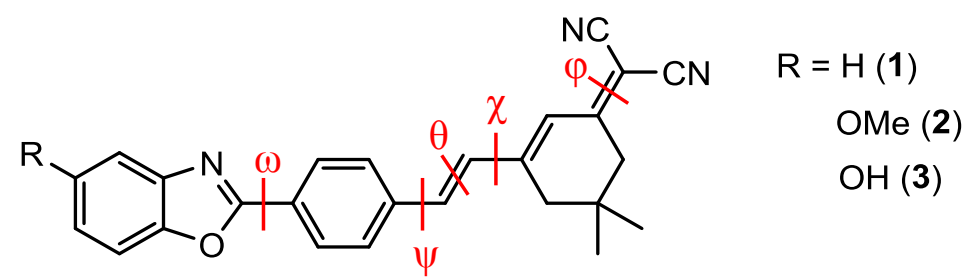

Fig. 1 Chemical structure of 2-styrylbenzoxazole derivatives, with relevant bonds specified in red.

\section{Experimental}

\subsection{Materials and synthesis}

All reagent grade chemicals obtained from Fisher Scientific and Sigma-Aldrich were used without further purification. The reactions were monitored by thin-layered chromatography (TLC) using $0.2 \mathrm{~mm}$ Alugram Xtra silica gel 60 F254 pre-coated sheets. Chromatographic purifications were made using silica gel $(63-200 \mu \mathrm{m}$, porosity $60 \AA$ ) purchased from $\mathrm{MN}$ and alumina gel grade 4, previously prepared from aluminum oxyde ( $90 \AA$, activity 1$)$ from MN.

\subsection{1. (E)-2-(3-(4-(5-methoxybenzo[d]oxazol-2-yl)styryl)-5,5-dimethylcyclohex-2-en-1-ylidene) malononitrile (2)}

To a solution of 2-amino-4-methoxyphenol $(0.3 \mathrm{~g}, 2.15 \mathrm{mmol})$ in absolute ethanol $(70 \mathrm{~mL})$ was added terephthalaldehyde $(0.5 \mathrm{~g}, 3.73 \mathrm{mmol})$. The reaction mixture was heated to $50{ }^{\circ} \mathrm{C}$ for $5 \mathrm{~h}$, and then the solvent was removed under reduced pressure. The obtained solid was dissolved in dichloromethane (42 mL), 2,3-dichloro-5,6-dicyano-1,4-benzoquinone (DDQ) (0.5 g, $2.2 \mathrm{mmol}$ ) was added, and the reaction mixture was stirred at room temperature for $14 \mathrm{~h}$. It was treated with saturated sodium carbonate aqueous solution $(10 \mathrm{~mL})$, and then with saturated sodium chloride solution (10 $\mathrm{mL}$ ). The solvent was removed under reduced pressure. The crude product was sublimated to remove terephthalaldehyde and 4-(5-methoxybenzo[ $d]$ oxazol-2-yl)benzaldehyde was purified by column chromatography using silica gel and dichloromethane/petroleum ether (8:2) as eluent. Yield: $45 \%$.

An aliquot of this aldehyde $(0.1 \mathrm{~g}, 0.39 \mathrm{mmol})$ was dissolved in absolute ethanol $(4.5 \mathrm{~mL})$, and 2-(3,5,5-trimethylcyclohex-2-en-1-ylidene)malononitrile $(0.09 \mathrm{~g}, 0.48 \mathrm{mmol})$ and piperidine (11 $\mu \mathrm{L})$ were added. The reaction mixture was refluxed for $14 \mathrm{~h}$ under argon, and then filtered and washed with diethyl ether $(10 \mathrm{~mL})$. The filtrate was collected and the solvent was evaporated, giving a yelloworange dye that was purified by column chromatography using alumina gel and petroleum ether/dichloromethane 55:45 as eluent system. Yield: 60\%. 
$\mathrm{Mp}=231.4{ }^{\circ} \mathrm{C}$. FTIR $\left(\mathrm{cm}^{-1}\right): 3031\left(v_{\mathrm{C}-\mathrm{H}}\right), 2219\left(v_{\mathrm{C} \equiv \mathrm{N}}\right), 1614\left(v_{\mathrm{C}=\mathrm{N}}\right), 1548\left(v_{\mathrm{C}-\mathrm{N}=\mathrm{C}-\mathrm{O}}\right), 1416-1480$ $\left(v_{\mathrm{C}-\mathrm{C}}\right), 1125\left(v_{\mathrm{C}-\mathrm{O}}\right) .{ }^{1} \mathrm{H}$ NMR $\left(\mathrm{CDCl}_{3}, 300 \mathrm{MHz}\right): \delta \mathrm{ppm}=1.09\left(\mathrm{~s}, 6 \mathrm{H}, 2 \mathrm{CH}_{3}\right), 2.48\left(\mathrm{~s}, 2 \mathrm{H}, \mathrm{CH}_{2}\right), 2.61$ $\left(\mathrm{s}, 2 \mathrm{H}, \mathrm{CH}_{2}\right), 3.88\left(\mathrm{~s}, 3 \mathrm{H}, \mathrm{CH}_{3}\right), 6.89(\mathrm{~s}, 1 \mathrm{H}$, vinylic-H), $6.97(\mathrm{dd}, J=8.9,2.5 \mathrm{~Hz}, 1 \mathrm{H}, \operatorname{arH}), 7.08$ (s, $2 \mathrm{H}$, vinylic-H), $7.25(\mathrm{~d}, J=2.5 \mathrm{~Hz}, 1 \mathrm{H}, \operatorname{arH}), 7.47(\mathrm{~d}, J=8.9 \mathrm{~Hz}, 1 \mathrm{H}, \operatorname{arH}), 7.63-7.65(\mathrm{~m}, 2 \mathrm{H}, \operatorname{arH})$, 8.22-8.25 (m, $2 \mathrm{H}$, arH $) .{ }^{13} \mathrm{C} \mathrm{NMR}\left(\mathrm{CDCl}_{3}, 75 \mathrm{MHz}\right): \delta \mathrm{ppm}=28.2\left(2 \mathrm{CH}_{3}\right), 32.2(\mathrm{Cq}), 39.3\left(\mathrm{CH}_{2}\right)$, $43.1\left(\mathrm{CH}_{2}\right), 56.1\left(\mathrm{CH}_{3}\right), 79.7(\mathrm{Cq}), 103.0(\mathrm{CH}), 110.9(\mathrm{CH}), 112.7(\mathrm{Cq}), 113.4(\mathrm{Cq}), 114.3(\mathrm{CH}), 124.6$ $(\mathrm{CH}), 128.07(\mathrm{CH}), 128.1(\mathrm{Cq}), 128.13(\mathrm{CH}), 131.0(\mathrm{CH}), 135.7(\mathrm{CH}), 138.6(\mathrm{Cq}), 143.1(\mathrm{Cq}), 145.6$ $(\mathrm{Cq}), 153.2(\mathrm{Cq}), 157.7(\mathrm{Cq}), 163.2(\mathrm{Cq}), 169.1(\mathrm{Cq})$. HRMS $\left(\mathrm{ESI}^{+}\right): \mathrm{m} / \mathrm{z}$ calcd for $\mathrm{C}_{27} \mathrm{H}_{24} \mathrm{~N}_{3} \mathrm{O}_{2}([\mathrm{M}+$ $\mathrm{H}])^{+} 422.1869$, found 422.1873 .

\subsection{2. (E)-2-(3-(4-(5-hydroxybenzo[d]oxazol-2-yl)styryl)-5,5-dimethylcyclohex-2-en-1-ylidene) malononitrile (3)}

Compound 2 ( $85 \mathrm{mg}, 0.2 \mathrm{mmol})$ was dissolved in dry dichloromethane $(2 \mathrm{~mL}), \mathrm{BBr}_{3}(800 \mu \mathrm{L})$ was added dropwise and the reaction mixture was heated to $48{ }^{\circ} \mathrm{C}$ for $24 \mathrm{~h}$. After cooling, it was washed with a saturated solution of sodium hydrogen carbonate $(2 \mathrm{~mL})$, and then with water. Dichloromethane $(2 \mathrm{~mL})$ was added, the organic phase was washed with water and then dried over $\mathrm{MgSO}_{4}$. The solvent was evaporated and the orange dye was purified by column chromatography using silica gel and petroleum ether/acetone 75:25 as eluent system. For spectroscopic analysis the dye was further purified by semi-preparative HPLC (Autopurification Waters) using a BEH C18 $1.7 \mu \mathrm{m}$ $(2.1 \times 100) \mathrm{mm}$ column and a gradient of water and acetonitrile $(50: 50$ for $10 \mathrm{~min}$, then $100 \%$ acetonitrile) with a flow rate of $0.4 \mathrm{~mL} / \mathrm{min}$. The compound was eluted with a retention time of 4.18 min. The collected fractions were checked by analytical UPLC (UPLC Acquity Waters, column BEH C18) and pooled. Yield: $20 \%$.

$\mathrm{Mp}=238.8^{\circ} \mathrm{C} . \mathrm{IR}\left(\mathrm{cm}^{-1}\right): 3439\left(v_{\mathrm{O}-\mathrm{H}}\right), 2958\left(v_{\mathrm{C}-\mathrm{H}}\right), 2221\left(v_{\mathrm{C} \equiv \mathrm{N}}\right), 1611\left(v_{\mathrm{C}=\mathrm{N}}\right), 1556\left(v_{\mathrm{C}-\mathrm{N}=\mathrm{C}-\mathrm{O}}\right)$, 1417-1471 $\left(v_{\mathrm{C}=\mathrm{C}}\right) .{ }^{1} \mathrm{H}$ NMR (DMSO-d6, $\left.300 \mathrm{MHz}\right): \delta(\mathrm{ppm})=1.03\left(\mathrm{~s}, 6 \mathrm{H}, 2 \mathrm{CH}_{3}\right), 2.57\left(\mathrm{~s}, 2 \mathrm{H}, \mathrm{CH}_{2}\right)$, $2.63\left(\mathrm{~s}, 2 \mathrm{H}, \mathrm{CH}_{2}\right), 6.87(\mathrm{dd}, J=8.8,2.4 \mathrm{~Hz}, 1 \mathrm{H}, \operatorname{arH}), 6.97(\mathrm{~s}, 1 \mathrm{H}$, vinylic- $\mathrm{H}), 7.10(\mathrm{~d}, J=2.3 \mathrm{~Hz}, 1 \mathrm{H}$, $\operatorname{arH}), 7.35\left(\mathrm{~d}, J_{\mathrm{AB}}=16.2 \mathrm{~Hz}\right.$, part A of an $\mathrm{AB}$ system, $1 \mathrm{H}$, vinylic- $\left.\mathrm{H}\right), 7.58(\mathrm{~d}, J=8.7 \mathrm{~Hz}, 1 \mathrm{H}, \operatorname{arH})$, $7.59\left(\mathrm{~d}, J_{\mathrm{AB}}=16.2 \mathrm{~Hz}\right.$, part B of an AB system, $1 \mathrm{H}$, vinylic- $\left.\mathrm{H}\right), 7.89-7.92(\mathrm{~m}, 2 \mathrm{H}$, arH $), 8.15-8.18(\mathrm{~m}$, $2 \mathrm{H}, \operatorname{arH}), 9.59(\mathrm{~s}, 1 \mathrm{H}, \mathrm{OH}) .{ }^{13} \mathrm{C}$ NMR (DMSO-d6, $\left.75 \mathrm{MHz}\right): \delta(\mathrm{ppm})=27.5\left(2 \mathrm{CH}_{3}\right), 31.7(\mathrm{Cq}), 38.1$ $\left(\mathrm{CH}_{2}\right), 42.3\left(\mathrm{CH}_{2}\right), 77.2(\mathrm{Cq}), 104.7(\mathrm{CH}), 110.9(\mathrm{CH}), 112.9(\mathrm{Cq}), 113.8(\mathrm{Cq}), 114.2(\mathrm{CH}), 123.8$ $(\mathrm{CH}), 126.9(\mathrm{CH}), 127.5(\mathrm{CH}), 128.5(\mathrm{CH}), 131.6(\mathrm{CH}), 136.0(\mathrm{Cq}), 139.1(\mathrm{Cq}), 142.6(\mathrm{Cq}), 144.1$ $(\mathrm{Cq}), 155.1(\mathrm{Cq}), 155.2(\mathrm{Cq}), 162.3(\mathrm{Cq}), 170.2(\mathrm{Cq})$. HRMS $\left(\mathrm{ESI}^{+}\right): \mathrm{m} / \mathrm{z}$ calcd for $\mathrm{C}_{26} \mathrm{H}_{22} \mathrm{O}_{2} \mathrm{~N}_{3}([\mathrm{M}+$ $\mathrm{H}])^{+}$408.1712, found 408.1703 .

\subsection{Apparatus and methods}

The melting points were measured on a Melting Point System MP50 Mettler Toledo apparatus. Chemical characterizations were performed in the relevant services of Institut de Chimie de Toulouse (ICT). The ${ }^{1} \mathrm{H}$ NMR and ${ }^{13} \mathrm{C}$ NMR spectra were recorded on a Bruker AC300 spectrometer operating at $300 \mathrm{MHz}$ and $75 \mathrm{MHz}$, respectively. Chemical shifts are reported in ppm, with residual protonated solvents as internal references. High-resolution mass spectra (HRMS) were obtained on a Xevo G2 QTof Waters spectrometer. Infrared spectra were obtained using a Nexus ThermoNicolet FTIR spectrophotometer equipped with a diamond ATR.

Spectroscopic measurements in solution were conducted at $20^{\circ} \mathrm{C}$ in a temperature-controlled cell of $1 \mathrm{~cm}$ optical pathway. Both UV-visible absorption and fluorescence spectra were recorded with a Xenius SAFAS spectrofluorimeter. All fluorescence spectra were corrected. The relative fluorescence quantum yields $\left(\Phi_{\mathrm{F}}\right)$ of solutions were determined using the classical formula:

$\Phi_{\mathrm{Fx}}=\left(A_{\mathrm{s}} \times F_{\mathrm{x}} \times n_{\mathrm{x}}^{2} \times \Phi_{\mathrm{Fs}}\right) /\left(A_{\mathrm{x}} \times F_{\mathrm{s}} \times n_{\mathrm{s}}^{2}\right)$

where $A$ is the absorbance at the excitation wavelength, $F$ is the area under the fluorescence curve, and $n$ is the refraction index. Subscripts "s" and "x" refer to the standard and to the sample of unknown quantum yield, respectively. Coumarin $153\left(\Phi_{\mathrm{F}}=0.53\right)$ was taken as the standard [15]. The absorbance of the solutions was equal or below 0.05 at the excitation wavelength. The error on $\Phi_{\mathrm{Fx}}$ values is estimated to be about $10 \%$. For solid samples, PL was analyzed on the same apparatus using a $\mathrm{BaSO}_{4}$ 
integrating sphere. Solid samples were deposited on a metal holder. The excitation source was scanned in order to evaluate the reflected light for the empty sphere $\left(L_{\mathrm{a}}\right)$, the samples facing the source light $\left(L_{\mathrm{c}}\right)$ and the sample out of the irradiation beam $\left(L_{\mathrm{b}}\right)$. The luminescence spectra were recorded with the sample facing the source light $\left(E_{\mathrm{c}}\right)$ and out from direct irradiation $\left(E_{\mathrm{b}}\right)$. The PM voltage was adapted to the measurement of reflected light and emission spectra, respectively, and proper correction was applied to take into account the voltage difference. The absolute PL quantum yield values $\left(\Phi_{\mathrm{PL}}\right)$ were calculated by a method based on the one developed by de Mello et al. [16] using the formula:

$\Phi_{\mathrm{PL}}=\left[E_{\mathrm{c}}-(1-\alpha) E_{\mathrm{b}}\right] / L_{\mathrm{a}} \alpha$

with $\alpha=1-L_{\mathrm{c}} / L_{\mathrm{b}}$. The error on the $\Phi_{\mathrm{PL}}$ value was estimated to be about $20 \%$.

For scanning electron microscopy (SEM), specimens were prepared by adding a few drops of suspension onto conductive adhesive carbon tape stuck on an aluminum stub and dried overnight. Then, samples were gold-sputtered. The morphology of the solids was observed by a Jeol JMS 6360A scanning electron microscope at acceleration voltage of $10 \mathrm{kV}$.

\subsection{Crystallography}

Crystal data were collected at 193(2) K on a Bruker-AXS APEX II diffractometer equipped with a $30 \mathrm{~W}$ air-cooled microfocus source $(\operatorname{ImS})$ with focusing multilayer optics $(3)$ and on a BrukerAXS D8-Venture diffractometer equipped with a CMOS detector (1 and 2), using MoK $\alpha$ radiation $(\lambda$ $=0.71073 \AA$ A). The structures were solved using an intrinsic phasing method (ShelXT) [17].

Table 1. Selected crystallographic data of compounds $\mathbf{1}, \mathbf{2}$ and 3.

\begin{tabular}{|c|c|c|c|}
\hline & 1 & 2 & 3 \\
\hline Empirical formula & $\mathrm{C}_{26} \mathrm{H}_{21} \mathrm{~N}_{3} \mathrm{O}$ & $\mathrm{C}_{27} \mathrm{H}_{23} \mathrm{~N}_{3} \mathrm{O}_{2}$ & $\mathrm{C}_{26} \mathrm{H}_{21} \mathrm{~N}_{3} \mathrm{O}_{2}, 2\left(\mathrm{C}_{2} \mathrm{H}_{6} \mathrm{OS}\right)$ \\
\hline Formula weight & 391.46 & 421.48 & 563.71 \\
\hline Crystal system & Monoclinic & Triclinic & Triclinic \\
\hline Space group & $P 2_{1}$ & $P \overline{1}$ & $P \overline{1}$ \\
\hline \multicolumn{4}{|l|}{ Unit cell dimensions } \\
\hline $\mathrm{a}(\AA)$ & $6.1792(4)$ & $9.7197(9)$ & $8.8848(8)$ \\
\hline $\mathrm{b}(\AA)$ & $7.1677(5)$ & $11.3948(10)$ & $8.9460(8)$ \\
\hline$c(\AA)$ & $23.0531(15)$ & $12.0149(11)$ & $18.7321(19)$ \\
\hline$\alpha\left(^{\circ}\right)$ & 90 & $107.957(3)$ & $82.740(3)$ \\
\hline$\beta\left(^{\circ}\right)$ & $91.492(2)$ & $102.352(3)$ & $82.215(3)$ \\
\hline$\gamma\left({ }^{\circ}\right)$ & 90 & $112.096(3)$ & $86.507(3)$ \\
\hline Volume $\left(\AA^{3}\right)$ & $1020.69(12)$ & $1087.66(17)$ & $1461.9(2)$ \\
\hline $\mathrm{Z}$ & 2 & 2 & 2 \\
\hline Crystal size $\left(\mathrm{mm}^{3}\right)$ & $0.520 \times 0.240 \times 0.080$ & $0.400 \times 0.250 \times 0.150$ & $0.200 \times 0.140 \times 0.050$ \\
\hline Reflections collected/independent & $26674 / 5099$ & $42330 / 5381$ & $48663 / 6965$ \\
\hline $\mathrm{R}(\mathrm{int})$ & 0.0610 & 0.0224 & 0.0850 \\
\hline Parameters/Restraints & $274 / 1$ & $292 / 0$ & $361 / 0$ \\
\hline Final $R_{1}$ indices $I>2 \sigma(I)$ & 0.0403 & 0.0420 & 0.0607 \\
\hline $\mathrm{wR}_{2}$ all data & 0.0974 & 0.1175 & 0.1501 \\
\hline Largest diff. peak and hole $\left(\mathrm{e} . \AA^{-3}\right)$ & 0.154 and -0.150 & 0.299 and -0.226 & 0.251 and -0.368 \\
\hline $\mathrm{CCDC}$ & 2013577 & 2013578 & 2013579 \\
\hline
\end{tabular}


All non-hydrogen atoms were refined anisotropically using the least-squares method on $\mathrm{F}^{2}[18]$. Hydrogen atoms were refined isotropically at calculated positions using a riding model with their isotropic displacement parameters constrained to be equal to 1.5 times the equivalent isotropic displacement parameters of their pivot atoms for terminal $\mathrm{sp}^{3}$ carbon and 1.2 times for all other carbon atoms. $\mathrm{H}$ atom on $\mathrm{O}(\mathbf{3})$ was located by difference Fourier maps and freely refined. Molecular graphics were generated using the MERCURY software [19]. Selected crystallographic data are collected in Table 1, molecular views are given in Fig. 2. CCDC supplementary crystallographic data can be obtained free of charge from The Cambridge Crystallographic Data Centre via https://www.ccdc.cam.ac.uk/structures.

\section{Results and discussion}

\subsection{Synthesis}

For the synthesis of dyes $\mathbf{1}$ and 2, 4-(benzo[ $d]$ oxazol-2-yl)benzaldehyde and its methoxylated analogue were obtained by condensation of the corresponding 2-aminophenol with terephthalaldehyde, and then reacted with 2,3-dichloro-5,6-dicyano-1,4-benzoquinone (DDQ). The desired compounds were obtained with a correct yield of $60 \%$. Dye 3 was prepared by reacting 2 with $\mathrm{BBr}_{3}$, according to a one-pot procedure (Fig. S1, ESI $\uparrow$ ) [20, 21]. The yield was poor (20\%), but it is known that the yield of demethylation of aryl methyl ether by $\mathrm{BBr}_{3}$ suffers from unpredictable variability depending on the nature of aryl ether and reaction conditions [22]. The procedure was not optimized in the present work. The three compounds were purified by chromatography, and their purity was checked by TLC and HPLC; otherwise, the presence of highly emissive impurities leads to major variations of the spectroscopic properties.

\subsection{Crystallographic study}

Single crystals of $\mathbf{1}$ and $\mathbf{2}$ were grown by slow evaporation of dichloromethane solutions, while $\mathbf{3}$ crystallized as a solvate in dimethylsulphoxide. In the three cases, the aromatic system is almost planar (slighty twisted between the benzoxazole and 5,5-dimethylcyclohexenylidene group for molecules $\mathbf{1}$ and $\mathbf{2}$, and slightly bent in molecule $\mathbf{3}$ ), denoting a high $\pi$-conjugation degree between the donor benzoxazole group and the acceptor nitrile groups (Fig. 2). The aliphatic moiety of the 5,5dimethylcyclohexenylidene group is clearly out of plane and brings some steric hindrance. For the three compounds, each molecule interacts with several adjacent molecules, along both the vertical and lateral directions.

The two molecules that constitute the unit cell of $\mathbf{1}$ are displayed in antiparallel orientation with an angle of $42^{\circ}$ between them (Fig. S2a $\uparrow$ ), leading to two distinctive molecular assemblies that result in the formation of thick layers. Molecules are arranged in slip-stacks along the short molecular axis, with a small slip along the long molecular axis. The network is structured by various $\mathrm{C} \cdots \mathrm{HC}$ interactions and by $\mathrm{N}^{\cdots} \mathrm{HC}$ interactions involving the benzoxazole heterocycle (Fig. 3a). For $\mathbf{2}$, the unit cell comprises two molecules that form a face-to-face antiparallel dimer where short contacts take place between the cyano and methoxy groups (Fig. S2b †). Besides, centrosymmetrically-related molecules associate via $\mathrm{N}^{\cdots} \mathrm{HC}$ and $\mathrm{O}{ }^{\cdots} \mathrm{HC}$ interactions that involve the benzoxazole and methoxy groups (Fig. 3b). In solvate $\mathbf{3}$, molecules are arranged along their long axis in antiparallel orientation (Fig. S2c †). Hydrogen bonds are formed between the hydroxy group and two DMSO molecules. The cyano groups interact with the vinylic hydrogen atom to form a centrosymmetric dimer between two coplanar molecules, and stacked dimers are slipped along both the long and short molecular axes (Fig. 3c). Remarkably, the crystal network is particularly compact for $\mathbf{2}$ and $\mathbf{3}$. By comparison, it has been reported that for dicyanovinyl derivatives the nitrogen atoms of the cyano groups are generally involved in intermolecular interactions, resulting either in densely knitted crystal networks [23-25], or in the formation of layers between coplanar molecules [9, 24, 25]. It must also be emphasized that for our three compounds, no $\pi$-stacking between aromatic moieties was observed. 

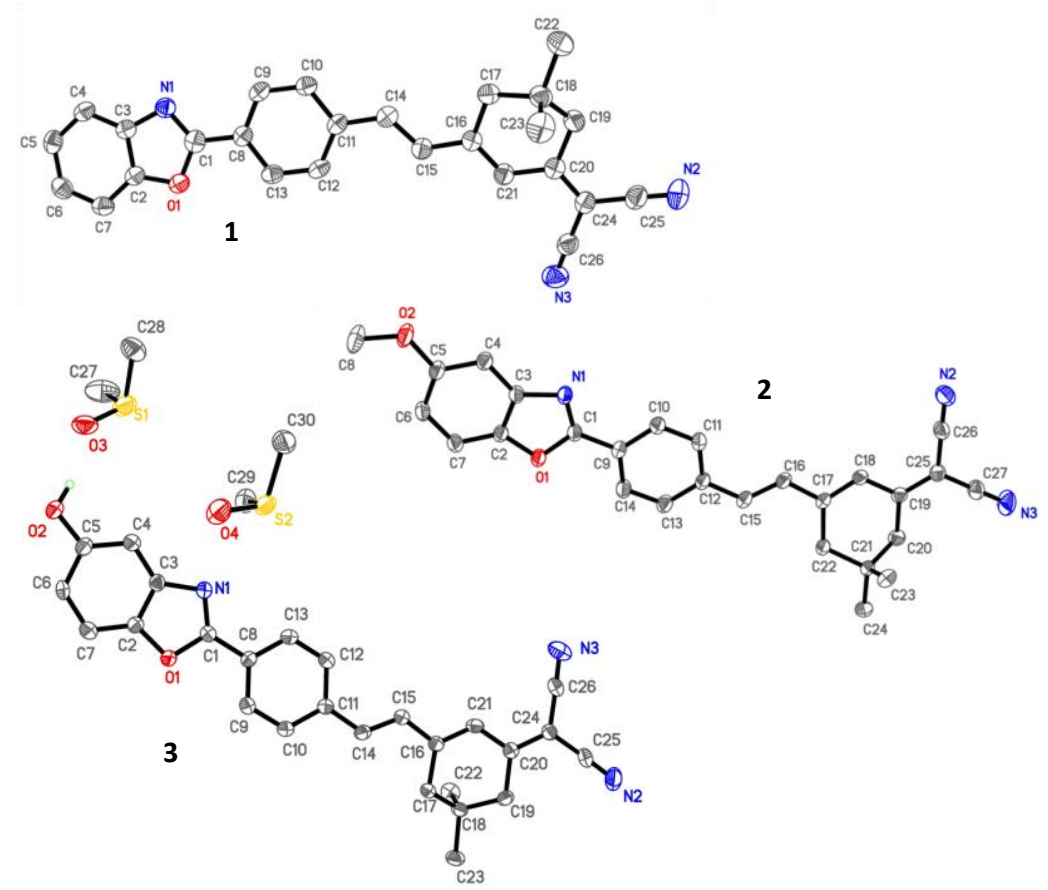

Fig. 2 Molecular views of the 2-styrylbenzoxazole derivatives $\mathbf{1}$ and 2, and asymmetric unit of 3. Thermal ellipsoids are drawn at the $50 \%$ probability level and $\mathrm{H}$ atoms are omitted for clarity (except $\mathrm{H}$ on $\mathrm{O}$ atoms in $\mathbf{3}$ ).
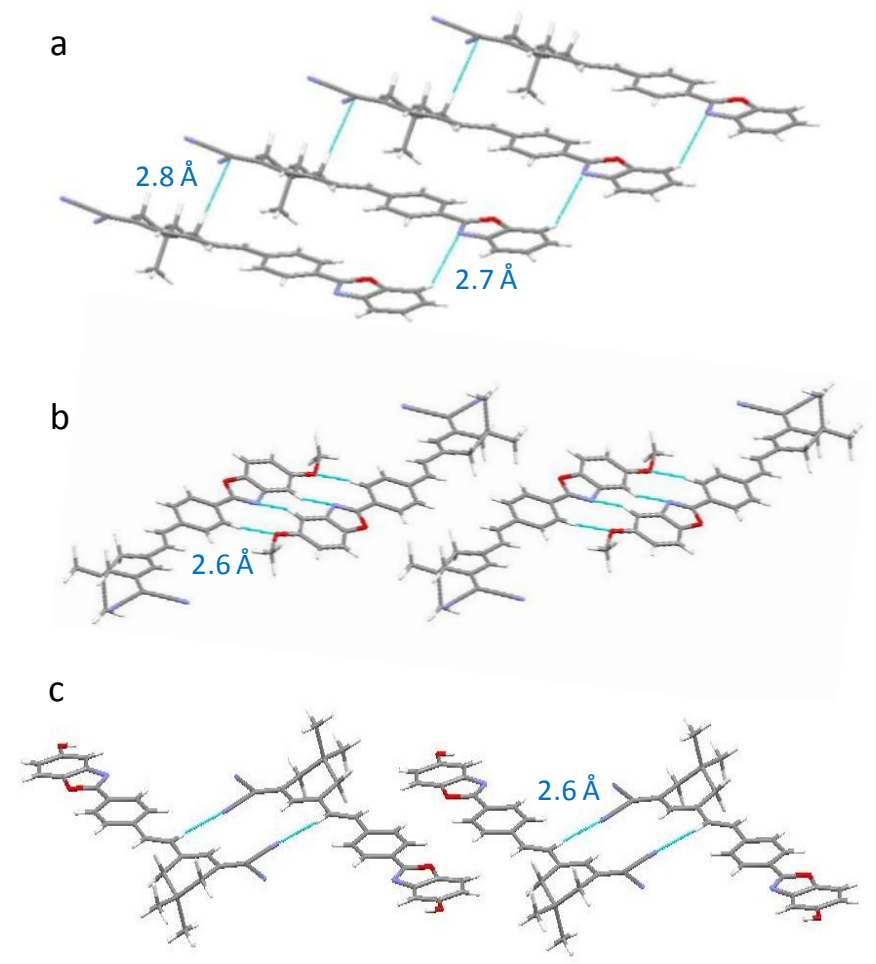

Fig. 3 Molecular arrangement of $\mathbf{1}$ (a), 2 (b) and $\mathbf{3}$ (c). Selected short contacts are indicated in blue ink.

\subsection{Spectroscopic study in solution}

The three dyes were briefly studied in tetrahydrofuran (THF), acetonitrile and ethanol solutions. All spectroscopic data are gathered in Table 2. The three compounds gave yellow solutions 
and had very close absorption spectra, with an intense unresolved band in the violet. The excitation spectra were independent of the emission wavelength, and conversely, the emission spectra did not depend on the excitation wavelength, showing the presence of only one emissive species responsible for absorption. As illustrated in Fig. 4, the emission spectra displayed a single band. The three compounds exhibit positive solvatochromic behavior, as reported by Yadav et al. for compound 1 [10]. The comparison between THF and acetonitrile showed that compounds $\mathbf{2}$ and $\mathbf{3}$ are particularly sensitive to an increase of polarity, possibly due to the electron donating effect of the methoxy and hydroxy groups. In contrast, no particular sensitivity to proticity was observed in ethanol. In fluid solvents, for every compound, the emission intensity was weak. But, when measurements were performed in glycerol/ethanol 90:10 v/v mixtures, the fluorescence efficiency was multiplied by four with respect to ethanol. This viscosity effect, comparable to that previously observed for dicyanovinylPBO [9], suggests that a large molecular motion in solution is responsible for fluorescence deactivation. By comparison with related molecules, several deactivation pathways may be envisaged. Since most of PBO derivatives are strongly fluorescent [5], it can be thought that rotations around the single bonds of the PBO moiety ( $\omega$ and $\psi$, Fig. 1) do not play a major role in the spectroscopic behaviour. In contrast, the rotation of the 5,5-dimethylcyclohex-2-en-1-ylidene)malononitrile moiety around the single bond $(\chi)$ could lead to much larger molecular motions, in line with the viscosity effect. It has been shown that this type of rotation may lead to a dark twisted internal charge transfer state (TICT) [26]. Willet and al. have also shown that a molecule close to ours undergoes an irreversible twist around the dicyanomethylene bond $(\varphi)$, which allows reaching a thermally accessible conical intersection $(\mathrm{CI})$, i.e. a region where the ground- and the excited-state potential energy surfaces (PESs) come into sufficiently close, so that non-radiative internal conversion is maximal [27]. Finally, the structural similarity to stilbenoid systems points to a deactivation also involving CI, due to a twist around the vinyl double bond $(\theta)[6,28,29]$. Identifying the deactivation mechanism involved would require sophisticated calculations and ultra fast spectroscopy measurements which are not within our reach. But in any cases, compounds 1-3 may be considered as molecular rotors [26].

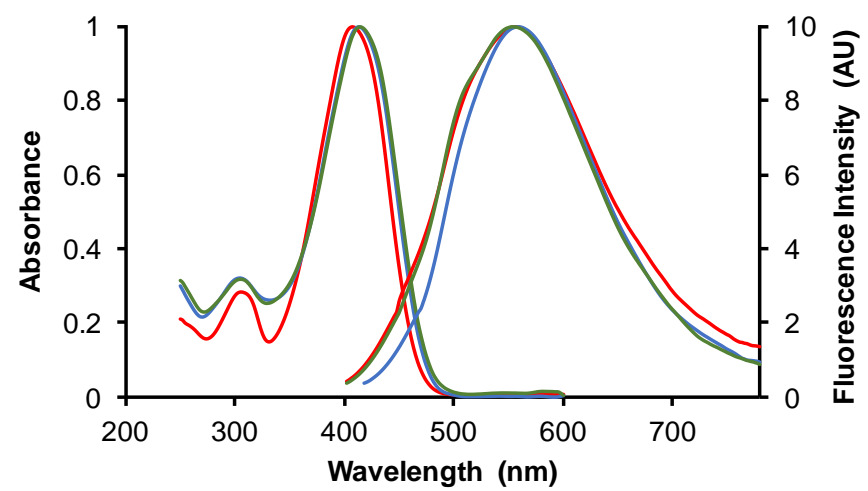

Fig. 4 Normalized UV-Vis absorption spectra (left) and fluorescence emission spectra (right) of dyes $\mathbf{1}$ (red lines), 2 (blue lines) and 3 (green lines) dissolved in THF. $\lambda_{\mathrm{ex}}=396 \mathrm{~nm}$. Concentration around $2 \times 10^{-5}$ for absorption and $1 \times 10^{-6}$ for emission.

\subsection{Nanoparticle suspensions}

Secondly, the PL properties of our compounds as nanoparticle suspensions were investigated. To do so, THF/water mixed solutions, containing the same dye concentration and various fractions of water $\left(f_{\mathrm{w}}\right)$, were stirred for $1 \mathrm{~h}$ after mixing, and then the emission spectra were recorded. It is noteworthy that longer period of time may afford slightly different results because of continuous evolution of the samples. As shown in Fig. 5, the emission intensity of $\mathbf{1}$ and $\mathbf{2}$ at the PL maximum wavelength was strongly enhanced up to 45 and 18 folds, respectively, in solutions containing a large proportion of water, while emissive particles were detected by fluorescence microscopy, suggesting clear SLE effect. For 3, no significant effect was observed. 
Table 2. Maximum absorption wavelength $\left(\lambda_{\text {abs }}\right)$, molar extinction coefficient $(\varepsilon)$, maximum emission wavelength $\left(\lambda_{\text {em }}\right)$, fluorescence and photoluminescence quantum yields $\left(\Phi_{\mathrm{F}}\right.$ and $\Phi_{\mathrm{PL}}$, respectively) for compound $\mathbf{1}, \mathbf{2}$ and $\mathbf{3}$ in various organic solvents and in the solid state. Dye concentration in solution around $2 \times 10^{-5}$ for absorption and $1 \times 10^{-6}$ for emission. Excitation at $396 \mathrm{~nm}$ for solutions and at $420 \mathrm{~nm}$ for solid state.

\begin{tabular}{|c|c|c|c|c|c|c|c|c|c|c|c|c|c|c|c|}
\hline \multirow[t]{2}{*}{ Compound } & \multicolumn{3}{|c|}{ THF } & \multicolumn{4}{|c|}{ Acetonitrile } & \multicolumn{3}{|c|}{ Ethanol } & \multicolumn{3}{|c|}{ Glycerol/Ethanol 90:10 } & \multicolumn{2}{|c|}{ Solid state $^{a}$} \\
\hline & $\begin{array}{c}\lambda_{\mathrm{abs}} \\
(\mathrm{nm})\end{array}$ & $\begin{array}{c}\lambda_{\mathrm{em}} \\
(\mathrm{nm})\end{array}$ & $\Phi_{\mathrm{F}}$ & $\left(\begin{array}{c}\varepsilon \\
\left(\mathrm{M}^{-1} \mathrm{~cm}^{-1}\right)\end{array}\right.$ & $\begin{array}{c}\lambda_{\mathrm{abs}} \\
(\mathrm{nm})\end{array}$ & $\begin{array}{c}\lambda_{\mathrm{em}} \\
(\mathrm{nm})\end{array}$ & $\Phi_{\mathrm{F}}$ & $\begin{array}{c}\lambda_{\mathrm{abs}} \\
(\mathrm{nm})\end{array}$ & $\begin{array}{c}\lambda_{\mathrm{em}} \\
(\mathrm{nm})\end{array}$ & $\Phi_{\mathrm{F}}$ & $\begin{array}{c}\lambda_{\mathrm{abs}} \\
(\mathrm{nm})\end{array}$ & $\begin{array}{c}\lambda_{\mathrm{em}} \\
(\mathrm{nm})\end{array}$ & $\Phi_{\mathrm{F}}$ & $\begin{array}{c}\lambda_{\mathrm{em}} \\
(\mathrm{nm})\end{array}$ & $\Phi_{\mathrm{PL}}$ \\
\hline 1 & 408 & 558 & $5.1 \times 10^{-3}$ & 55000 & 404 & 562 & $7.0 \times 10^{-3}$ & 406 & 568 & $7.0 \times 10^{-3}$ & 414 & 572 & $2.5 \times 10^{-2}$ & 606 & $2.8 \times 10^{-1}$ \\
\hline 2 & 412 & 560 & $6.5 \times 10^{-3}$ & 56900 & 408 & 586 & $8.3 \times 10^{-3}$ & 412 & 568 & $8.4 \times 10^{-3}$ & 418 & 576 & $3.4 \times 10^{-2}$ & 584 & $1.7 \times 10^{-1}$ \\
\hline 3 & 414 & 554 & $4.3 \times 10^{-3}$ & 48000 & 410 & 580 & $8.1 \times 10^{-3}$ & 414 & 564 & $8.2 \times 10^{-3}$ & 420 & 568 & $3.4 \times 10^{-2}$ & - & - \\
\hline
\end{tabular}

${ }^{a}$ as-prepared powders 
Noticeably, for 1, the emission maximum passed from $558 \mathrm{~nm}$ for solutions to $572 \mathrm{~nm}$ when suspension formed at $f_{w}=60 \%$, and then was gradually shifted to $584 \mathrm{~nm}$ at high water content. The behaviour of 2 was slightly more complex. In the five first samples, the maximum emission of solutions passed from 560 to $588 \mathrm{~nm}$ because of a polarity effect due to increased proportions of water. Then, the spectrum peaked at $546 \mathrm{~nm}$ with the formation of the first particles between $70 \%$ and $85 \%$ water, and was progressively red-shifted till $590 \mathrm{~nm}$ for the highest proportions of water. The wavelength shift observed for the particle formation was therefore much larger for $\mathbf{2}$ than for $\mathbf{1}$.

The samples where precipitation begins to be detected and the samples where precipitation is at its maximum were observed by scanning electron microscopy (SEM) (Fig. 6). For 1, micrometersized amorphous particles, some of them resembling empty rice grains, were observed at $f_{w}=60 \%$, while the sample at $f_{w}=95 \%$ contained agglomerates of cubic structures measuring several hundreds of nanometers. Emission at short wavelengths can therefore clearly been attributed to amorphous particles formed in the samples containing the lowest proportion of water, while emission at long wavelengths originates from microcrystals that quickly form and agglomerate in the samples containing the highest proportion of water. It is noteworthy that the behaviour of $\mathbf{1}$ is opposite to that reported for other AIE-active compounds, for which the proportion of amorphous structures vs microcrystals increases with increasing the water content [30,31]. For 2, both samples at $f_{w}=70$ and 95\% contained amorphous sheet-like particles, together with cubic particles that measured several micrometers. The coexistence of both amorphous and crystalline forms in every sample may explain
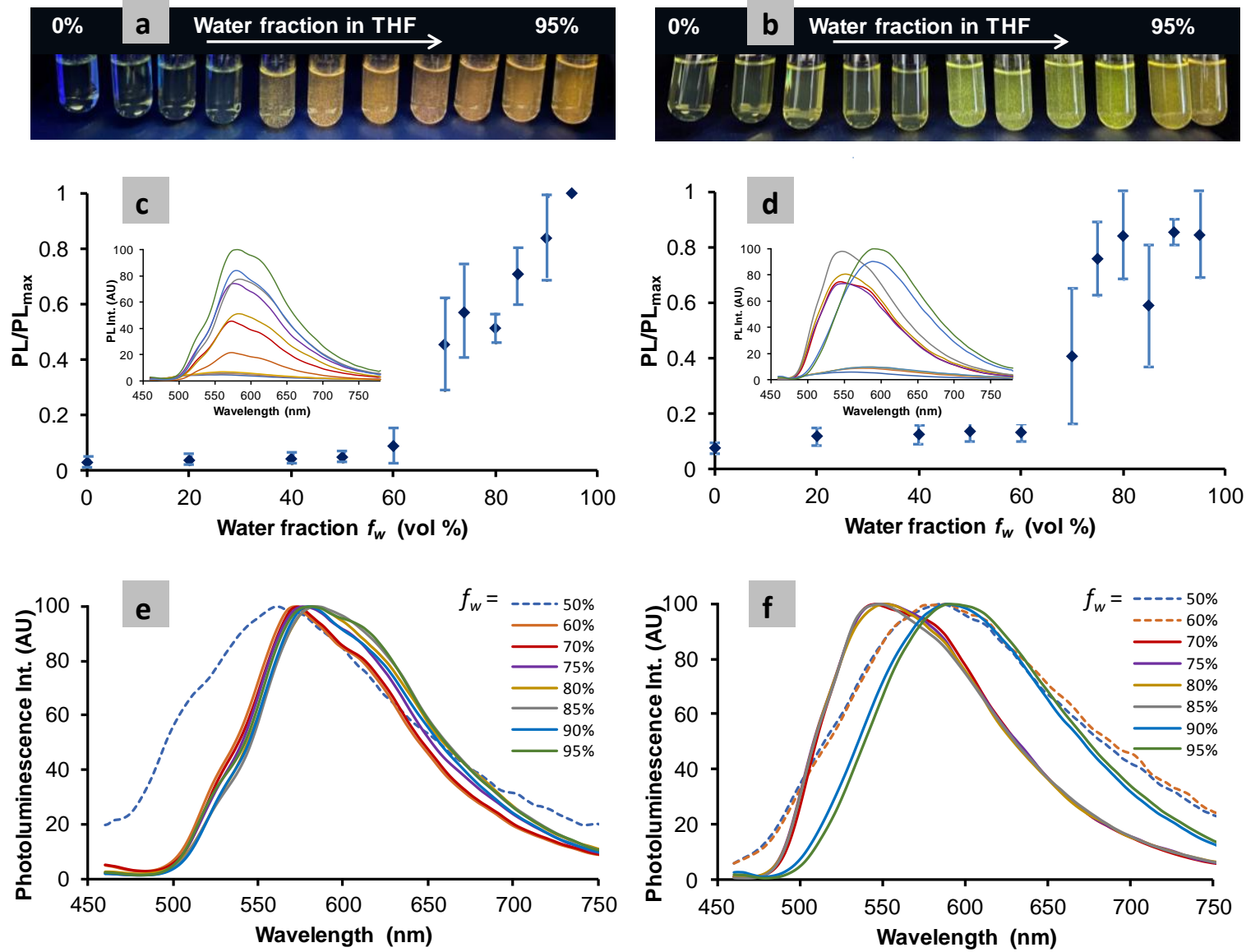

Fig. 5 Samples of dyes 1 (a) and 2 (b) in various THF/water mixtures, illuminated by a hand-held UV lamps $(365 \mathrm{~nm})$; Plot of the PL intensity ratio at $586 \mathrm{~nm}$ for dye $\mathbf{1}$ (c) and $590 \mathrm{~nm}$ for dye $\mathbf{2}$ (d) versus the water content in the solvent mixture (average of 3 measurements); Insets: Examples of the corresponding PL spectra; Normalized PL spectra of dyes 1 (e) and 2 (f) in various solvent mixtures $\left(f_{w}=0\right.$ to $40 \%$ not represented); arrows show the direction of the spectral shifts. The same colour code was used for all spectra. Dye concentration around $7 \times 10^{-6}$ M. $\lambda_{\mathrm{ex}}=440 \mathrm{~nm}$. 

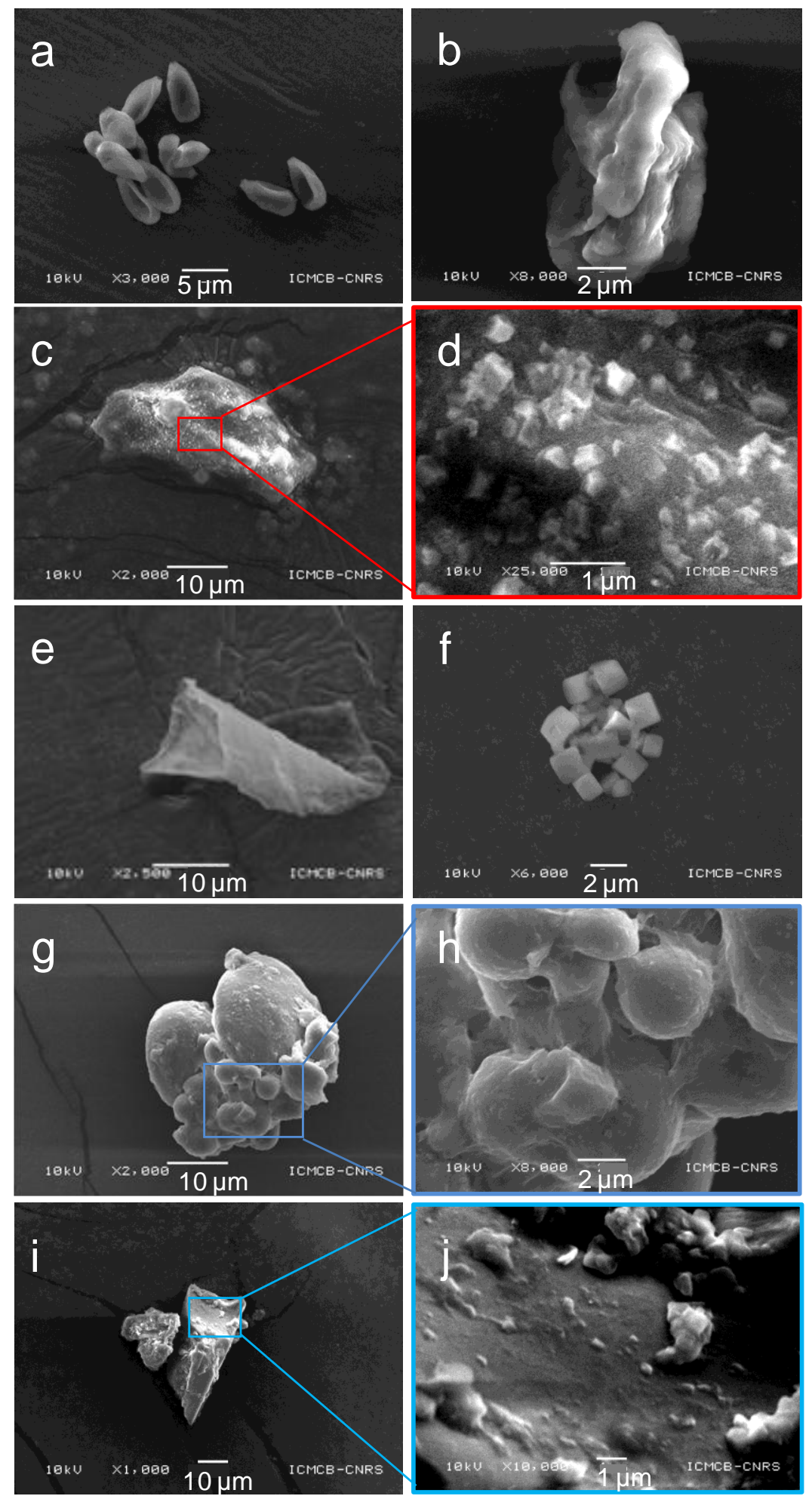

Fig. 6 Scanning electron microscopy images of suspensions of dyes $\mathbf{1}$ and $\mathbf{2}$ in various THF/water mixtures. Dye 1 at $f_{w}=60 \%(\mathrm{a}, \mathrm{b})$ and $95 \%(\mathrm{c}, \mathrm{d})$; Dye 2 at $f_{w}=70 \%(\mathrm{e}-\mathrm{h})$ and $95 \%(\mathrm{i}, \mathrm{j})$.

the large variations of the emission properties encountered from one experiment to another. Most probably, microcrystals dominate in suspensions of $\mathbf{2}$ at high water proportion, as is the case for $\mathbf{1}$, but this result was not confirmed by SEM.

Again, additional investigations would be necessary to identify the mechanism responsible for the SLE effect observed for $\mathbf{1}$ and $\mathbf{2}$. Restrictions of intramolecular rotations and motions (i.e. RIR and 
RIM mechanisms) upon aggregation have been initially evoked to explain the fluorescence revival observed in the aggregated state of AIE-active fluorophores, the idea being that the detrimental transfer of the electronic excitation energy to low frequency intramolecular rotational modes is blocked by molecular rigidification [7,8]. More recently, the restricted access to a conical intersection (RACI) model has been shown to apply to a large number of these fluorophores. According to this model, the energy of CI increases in the solid state due to steric constraints, so that radiationless decay is hindered [29]. Such a mechanism could very well take place in the present case.

\subsection{Microcrystalline powder emission}

To better understand how intermolecular interactions modulate the PL properties, the three asprepared powder compounds were studied in the solid state. All of them were intensely colourful. The reflectance spectra tailed until 570-600 nm (Fig. 7). When illuminated by a hand-held UV lamp (365 $\mathrm{nm}$ ), dyes 1 and $\mathbf{2}$ emitted strong orange and yellow light, respectively. The emission spectra of the pristine powders were centered on 606 and $584 \mathrm{~nm}$, respectively, with high PL quantum yields of 0.28 and 0.17 . The latter values are quite close to those estimated for nanoparticle suspensions, suggesting that fluorescence quenching by surface defects was not very significant in the present case [6]. The crystal structure indicates that no detrimental $\pi$-stacking interactions was observed for $\mathbf{1}$ and $\mathbf{2}$, which is in line with their strong emission. The slip-stacks arrangement of $\mathbf{1}$, with very few intermolecular interactions, seems to be an advantage for the PL properties, compared with the arrangement of 2 in which the methoxy group reinforces these interactions.

In contrast, dye $\mathbf{3}$ appeared almost dark under UV light, and the emission intensity was so weak that no accurate measurement could be performed using our spectrophotometer. Like in aggregates, this compound was not luminescent in the microcrystalline state. This was true for both the as-synthesized powder of unknown crystal structure, and for the DMSO solvate used for X-ray analysis. Regarding the molecular arrangement, the absence of $\pi$-stacking is not always an advantage for emission because it leads to lose packing [6], but this did not prevent the other two compounds to be luminescent. The major feature of $\mathbf{3}$ is the presence of the hydroxy group, prone to give hydrogen bonds. It is well known that H-bonds open non-radiative deactivation pathways in solutions [32-34]. However, they usually work in the opposite direction in the solid state, because they rigidify the molecular structures and activate the SLE processes of numerous fluorophores [35-37]. It must be noticed that most of these fluorophores undergo intramolecular proton transfer in the excited state (ESIPT). By comparison, other types of hydroxy-substituted fluorophores have received little attention because they are generally used as synthesis intermediates. A few reports indicate that some of them have good PL properties [38-40]. Nevertheless, the present observation shows that a hydroxy group on the benzoxazole heterocycle leads to non-luminescent solids, as was also the case for 5-hydroxyPBO [13]. This issue should merit broader examination. For example, it can be imagined that specific effects like partial de-protonation in the excited state modulate the electronic structure of $\mathbf{3}$ in an unfavorable manner to quench the PL. Another possibility is that the CI remains thermally accessible.

To complete this study, the influence of mechanical stimuli upon the PL properties [3, 41, 42] was investigated by grinding compounds $\mathbf{1}$ and $\mathbf{2}$ with a pestle in an agate mortar. For $\mathbf{1}$, only very weak variations were observed, so that mechanofluorochromism was readily discarded. This absence of MFC behaviour is probably due to the strong structuration of the crystal network, contrary to other cyano derivatives in which the molecules arrange in sheets that easily slip with respect to each other under gentle mechanical stimuli $[9,43]$, or lead to metastable materials rapidly evolving between amorphous and crystalline forms [44, 45]. The case of $\mathbf{2}$ was more intriguing. It is noteworthy that the spectroscopic properties of as-prepared powders of $\mathbf{2}$ varied from one sample to another. Upon grinding, the most coloured samples of 2 passed from yellow-orange to yellow, the emission spectrum was blue-shifted by $18 \mathrm{~nm}$ and the quantum yields was almost doubled (Fig. S3†). However, no reversibility upon heating or solvent fuming was observed, confirming the absence of MFC behaviour. Examination of the powders by optical and fluorescence microscopy showed the presence of thin microcrystals that emit intensely in the yellow, together with some thick crystals that emit orange light. The X-ray analysis indicated that both types of crystals have the same structure. The spectroscopic effect observed was therefore attributed to the size of microcrystals. Indeed, due to the overlap of the reflectance and PL spectra, reabsorption of the emitted light may easily occur in thick 
crystals, reducing the short-wavelength component of the emission spectrum [9]. This effect was particularly strong for $\mathbf{2}$ because the overlap of spectra was large, and the microcrystals very heterogeneous in size. It may also partly explain the strong red-shift observed for $\mathbf{2}$ in the AIE experiment, because of formation of large microcrystals and agglomerates of particles at high water proportion.
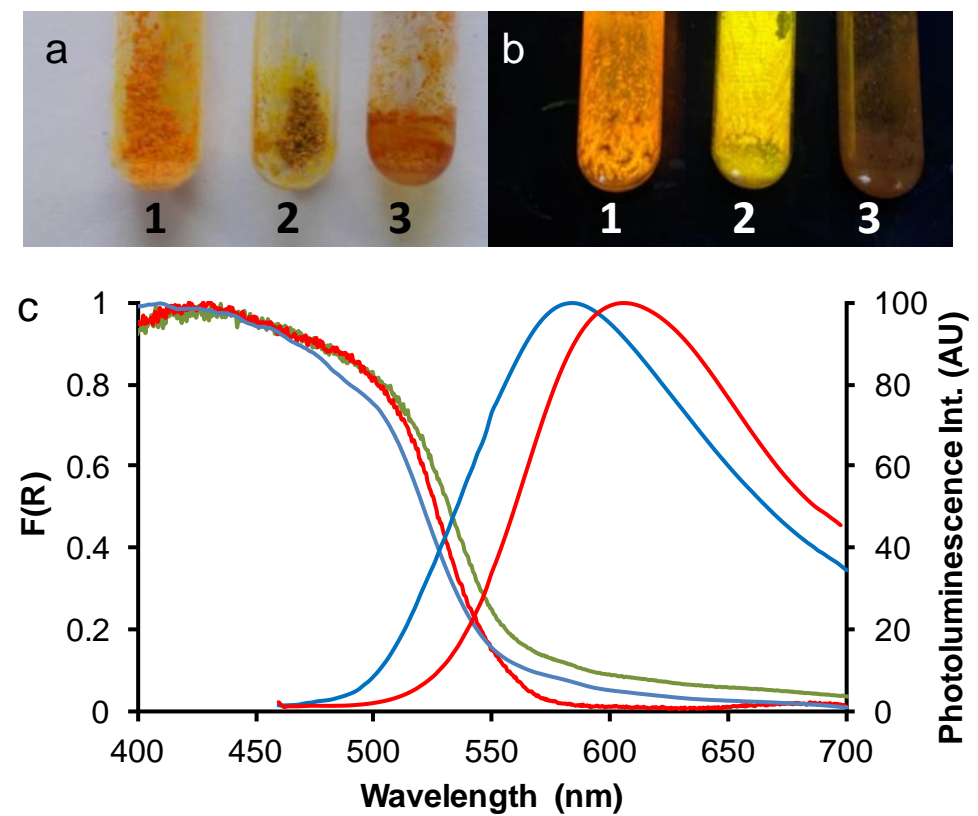

Fig. 7 a) Pictures of as-prepared powders of $\mathbf{1}, \mathbf{2}$ and $\mathbf{3}$ observed under day light and b) using a UV lamp (365 $\mathrm{nm}$ ). c) Corresponding reflectance spectra $(\mathrm{R}(\mathrm{F})$ ) of $\mathbf{1}$ (red line), $\mathbf{2}$ (blue line) and $\mathbf{3}$ (green line), and PL spectra of 1 and 2 with the same colour code (3 virtually not emissive, not represented). $\lambda_{\mathrm{ex}}=420 \mathrm{~nm}$.

\section{Conclusion}

This study confirms that minor chemical modifications may drastically influence the PL properties of compounds, which have nonetheless very close properties in solution. In the solid state, the presence of a methoxy group on the benzoxazole heterocycle is not an advantage for PL with respect to unsubstituted parent compound, and the presence of a hydroxy group is very detrimental and must be avoided. The latter behaviour is quite unusual and seems to be specific of PBO derivatives. Compound 1 appears as the most valuable derivative in this series of dyes. The strong SLE effect and the absence of MFC make this compound well suited for subsequent studies aimed at comparing various systems used for the preparation of crystalline nanoparticles of organic compounds.

\section{Acknowledgements}

ANR is gratefully acknowledged for funding (SUPERFON project \# ANR-17-CE07-0029-03).

\section{Appendix A. Supplementary data}

Electronic supplementary information (ESI) available: Scheme of synthesis, crystal asymmetric units, photoluminescence spectra. 


\section{References}

[1] S.P. Anthony, Organic Solid-State Fluorescence: Strategies for Generating Switchable and Tunable Fluorescent Materials, ChemPlusChem 77 (2012) 518-531.

[2] S. Varughese, Non-covalent routes to tune the optical properties of molecular materials, J. Mater. Chem. C 2 (2014) 3499-3516.

[3] C. Wang, Z. Li, Molecular conformation and packing: their critical roles in the emission performance of mechanochromic fluorescence materials, Mater. Chem. Front. 1 (2017) 2174-2194.

[4] J. Gierschner, L. Lüer, B. Milián-Medina, D. Oelkrug, H.-J. Egelhaaf, Highly Emissive H-Aggregates or Aggregation-Induced Emission Quenching? The Photophysics of All-Trans para-Distyrylbenzene, J. Phys. Chem. Lett. 4 (2013) 2686-2697.

[5] C. Carayon, S. Fery-Forgues, 2-Phenylbenzoxazole derivatives: a family of robust emitters of solid-state fluorescence, Photochem. Photobiol. Sci. 16 (2017) 1020-1035.

[6] J. Shi, L.E. Aguilar Suarez, S.-J. Yoon, S. Varghese, C. Serpa, S.Y. Park, L. Lüer, D. Roca-Sanjuán, B. MiliánMedina, J. Gierschner, Solid State Luminescence Enhancement in $\pi$-Conjugated Materials: Unraveling the Mechanism beyond the Framework of AIE/AIEE, J. Phys. Chem. C 121 (2017) 23166-23183.

[7] J. Mei, N.L.C. Leung, R.T.K. Kwok, J.W.Y. Lam, B.Z. Tang, Aggregation-Induced Emission: Together We Shine, United We Soar! Chem. Rev. 115 (2015) 11718-11940.

[8] J. Mei, Y. Huang, H. Tian, Progress and Trends in AIE-Based Bioprobes: A Brief Overview, ACS Appl. Mater. Interfaces 10 (2018) 12217-12261.

[9] C. Carayon, A. Ghodbane, N. Leygue, J. Wang, N. Saffon-Merceron, R. Brown, S. Fery-Forgues, Mechanofluorochromic Properties of an AIEE-Active 2-Phenylbenzoxazole Derivative: More than Meets the Eye? ChemPhotoChem 3 (2019) 545-553 and references therein.

[10] U.N. Yadav, H.S. Kumbhar, S.S. Deshpande, S.K. Sahoo, G.S. Shankarling, Photophysical and thermal properties of novel solid state fluorescent benzoxazole based styryl dyes from a DFT study, RSC Adv. 5 (2015) 42971-42977.

[11] N. Abid-Jarraya, H. Turki-Guermazi, K. Khemakhem, S. Abid, N. Saffon, S. Fery-Forgues, Investigations in the methoxy-iminocoumarin series: Highly efficient photoluminescent dyes and easy preparation of green-emitting crystalline microfibers, Dye Pigm. 101 (2014) 164-171.

[12] K. Khemakhem, M. Soulié, R. Brousses, H. Ammar, S. Abid, S. Fery-Forgues, Small Iminocoumarin Derivatives as Red Emitters: From Biological Imaging to Highly Photoluminescent Non-doped Micro- and Nanofibres, Chem. Eur. J. 21 (2015) 7927-7937.

[13] E. Bremond, N. Leygue, N. Saffon-Merceron, S. Fery-Forgues, 2-Phenylbenzoxazole Derivatives as Solid-State Fluorescence Emitters: Influence of Steric Hindrance and Hydrogen Bonding on the Optical Properties, Spectrochimica Acta 227 (2020) 117586.

[14] Q. Qi, Y. Liu, X. Fang, Y. Zhang, P. Chen, Y. Wang, B. Yang, B. Xu, W. Tian, S. X.-A. Zhang, AIE (AIEE) and mechanofluorochromic performances of TPE-methoxylates: effects of single molecular conformations, RSC Adv. 3 (2013) 7996-8002.

[15] K. Suzuki, A. Kobayashi, S. Kaneko, K. Takehira, T. Yoshihara, H. Ishida, Y. Shiina, S. Oishi, S. Tobita, Reevaluation of absolute luminescence quantum yields of standard solutions using a spectrometer with an integrating sphere and a back-thinned CCD detector, Phys. Chem. Chem. Phys. 11 (2009) 9850-9860.

[16] J.C. De Mello, H. F. Wittmann, R. H. Friend, An improved experimental determination of external photoluminescence quantum efficiency, Adv. Mater. 9 (1997) 230-232.

[17] G.M. Sheldrick, SHELXT-Integrated space-group and crystal-structure determination, Acta Crystallogr. A 71 (2015) 3-8.

[18] G.M. Sheldrick, Crystal structure refinement with SHELXL, Acta Crystallogr. C 71 (2015) 3-8.

[19] C.F. Macrae, P.R. Edgington, P. McCabe, E. Pidcock, G.P. Shields, R. Taylor, M. Towler, J. van de Streek, Mercury: Visualization and Analysis of Crystal Structures, J. Appl. Cryst. 39 (2006) 453-457.

[20] J.E. Donello, R. Yang, B. Leblond, E. Beausoleil, A.-S. Casagrande, L.J.R. Desiré, M.P. Pando, C. Chauvignac, T. Taverne, Substituted 6,7-dialkoxy-3-isoquinolinol derivatives as inhibitors of phosphodiesterase 10 (PDE10A), Patent WO 2012/112946 A1.

[21] J. Chen, C.Z. Ding, P. Dragovich, B. Fauber, Z. Gao, S. Labadie, K.W. Lai, H.E. Purkey, K. Robarge, B. Wei, A. Zhou, Piperidine-dione derivatives, Patent WO 2015/140133 A1.

[22] J.B. Press, Deethylation of aryl ethers by boron tribromide, Synth. Commun. 9 (1979) 407-410.

[23] Shweta, A. Kumar, Neeraj, S.K. Asthana, A. Prakash, J.K. Roy, I. Tiwari, K.K. Upadhyay, A highly sensitive naphthaoxazole-based cell-permeable ratiometric chemodosimeter for hydrazine, RSC Adv. 6 (2016) 9495994966.

[24] C. Botta, S. Benedini, L. Carlucci, A. Forni, D. Marinotto, A. Nitti, D. Pasini, S. Righetto, E. Cariati, Polymorphism-dependent aggregation induced emission of a push-pull dye and its multi-stimuli responsive behavior, J. Mater. Chem. C 4 (2016) 2979-2989. 
[25] S. Chen, H. Liu, Y. Li, D. Li, Y. Li, Tuning Luminescence and Conductivity through Controlled Growth of Polymorphous Molecular Crystals, Adv. Electron. Mater. 3 (2017) 1700132.

[26] T. Suhina, S. Amirjalayer, B. Mennucci, S. Woutersen, M. Hilbers, D. Bonn, A.M. Brouwer, Excited-State Decay Pathways of Molecular Rotors: Twisted Intermediate or Conical Intersection? J. Phys. Chem. Lett. 7 (2016) 4285-4290 and references cited.

[27] K.A. Willets, P.R. Callis, W.E. Moerner, Experimental and Theoretical Investigations of Environmentally Sensitive Single-Molecule Fluorophores, J. Phys. Chem. B 108 ( 2004) 10465-10473.

[28] B. G. Levine, T.J. Martínez, Isomerization Through Conical Intersections, Annu. Rev. Phys. Chem. 58 (2007) $58,613-634$.

[29] R. Crespo-Otero, Q. Li, L. Blancafort, Exploring Potential Energy Surfaces for Aggregation-Induced Emission-From Solution to Crystal, Chem. Asian J. 14 (2019) 700-714.

[30] X. Luo, J. Li, C. Li, L. Heng, Y.Q. Dong, Z. Liu, Z. Bo, B.Z. Tang, Reversible Switching of the Emission of Diphenyldibenzofulvenes by Thermal and Mechanical Stimuli, Adv. Mater. 23 (2011) 3261-3265.

[31] H. Tong, Y. Hong, Y. Dong, Y. Ren, M. Häussler, J.W.Y. Lam, K.S. Wong, B.Z. Tang, Aggregation-Induced Emission: Effects of Molecular Structure, Solid-State Conformation, and Morphological Packing Arrangement on Light-Emitting Behaviors of Diphenyldibenzofulvene Derivatives, J. Phys. Chem. B 111 (2007) 2000-2007.

[32] G.-J. Zhao, K.-L. Han, Hydrogen Bonding in the Electronic Excited State, Acc. Chem. Res. 45 (2012) $404-413$.

[33] S.F. Lee, Q. Vérolet, A. Fürstenberg, Improved super-resolution microscopy with oxazine fluorophores in heavy water, Angew. Chem. Int. Ed. 52 (2013) 8948-8951, and ref. herein.

[34] S. Xie, S. Manuguri, O. Ramström, M. Yan, Impact of Hydrogen Bonding on the Fluorescence of N-Amidinated Fluoroquinolones, Chem. Asian J. 14 (2019) 910-916.

[35] L. Wang, Y. Shen, M. Yang, X. Zhang, W. Xu, Q. Zhu, J. Wu, Y. Tian, H. Zhou, Novel highly emissive Haggregates with aggregate fluorescence change in a phenylbenzoxazole-based system, Chem. Commun. 50 (2014) 8723-8726.

[36] M. Wang, C. Cheng, J. Song, J. Wang, X. Zhou, H. Xiang, J. Liu, Multiple Hydrogen Bonds Promoted ESIPT and AIE-active Chiral Salicylaldehyde Hydrazide, Chin. J. Chem. 36 (2018) 698-707.

[37] X. Qiu, Y. Xu, C. Wang, M. Hanif, J. Zhou, C. Zeng, Y. Li, Q. Jiang, R. Zhao, D. Hu, Y. Ma, Synergistic effects of hydrogen bonds and the hybridized excited state observed for high-efficiency, deep-blue fluorescent emitters with narrow emission in OLED applications, J. Mater. Chem. C 7 (2019) 5461-5467.

[38] N. Pradhan, D. Jana, B.K. Ghorai, N. R. Jana, Detection and Monitoring of Amyloid Fibrillation Using a Fluorescence "Switch-On" Probe, ACS Appl. Mater. Interfaces 7 (2015) 25813-25820.

[39] Y. Li, Y. Lei, L. Dong, L. Zhang, J. Zhi, J. Shi, B. Tong, Y. Dong, 1,2,5-Triphenylpyrrole Derivatives with Dual Intense Photoluminescence in Both Solution and the Solid State: Solvatochromism and Polymorphic Luminescence Properties, Chem. Eur. J. 25 (2019) 573-581.

[40] A. Kathiravan, K. Sundaravel, M. Jaccob, G. Dhinagaran, A. Rameshkumar, D.A. Ananth, T. Sivasudha, Pyrene Schiff Base: Photophysics, Aggregation Induced Emission, and Antimicrobial Properties, J. Phys. Chem. B 118 (2014) 13573-13581.

[41] Y. Sagara, S. Yamane, M. Mitani, C. Weder, T. Kato, Mechanoresponsive Luminescent Molecular Assemblies: An Emerging Class of Materials, Adv. Mater. 28 (2016) 1073-1095.

[42] Z. Ma, Z. Wang, M. Teng, Z. Xu, X. Jia, Mechanically Induced Multicolor Change of Luminescent Materials, ChemPhysChem, 16 (2016) 1811-1828.

[43] S.-J. Yoon, J.W. Chung, J. Gierschner, K.S. Kim, M.-G. Choi, D. Kim, S.Y. Park, Multistimuli Two-Color Luminescence Switching via Different Slip-Stacking of Highly Fluorescent Molecular Sheets, J. Am. Chem. Soc. 132 (2010) 13675-13683.

[44] Y. Jiang, D. Gindre, M. Allain, P. Liu, C. Cabanetos, J. Roncali, A Mechanofluorochromic Push-Pull Small Molecule with Aggregation-Controlled Linear and Nonlinear Optical Properties, Adv. Mater. 27 (2015) 42854289.

[45] J.N. Zhang, H. Kang, N. Li, S.M. Zhou, H.M. Sun, S.W. Yin, N. Zhao, B.Z. Tang, Organic solid fluorophores regulated by subtle structure modification: color-tunable and aggregation-induced emission, Chem. Sci. 8 (2017) 577-582. 

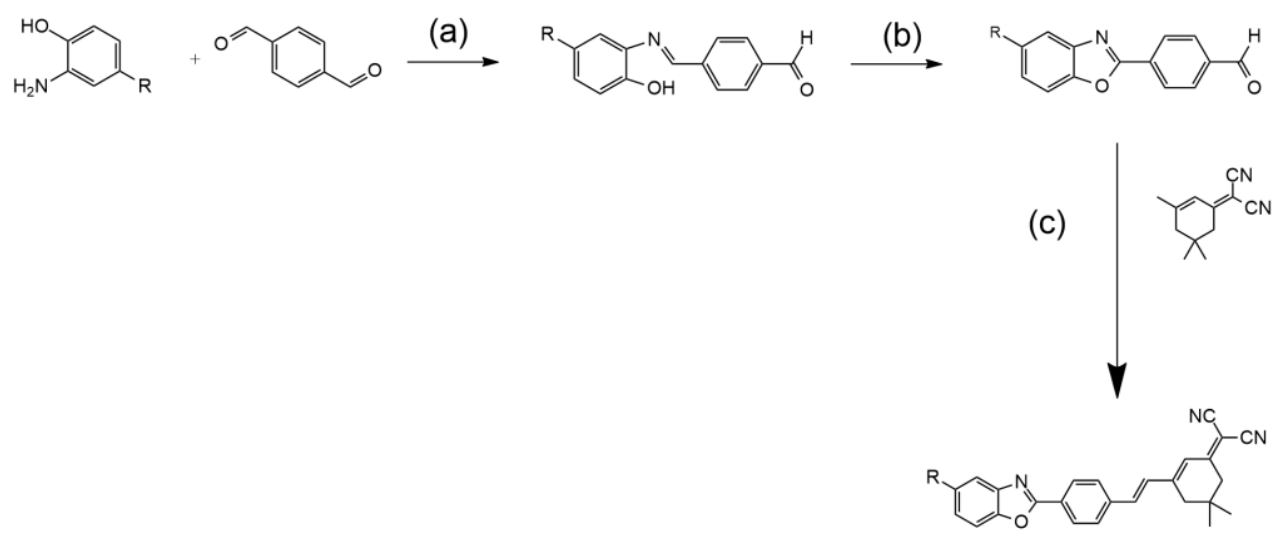

R: H (1)

R: OMe (2)

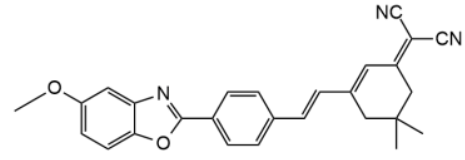

(2) (d)

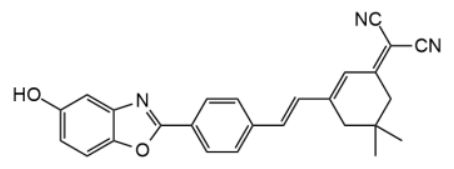

(3)

Figure S1. Synthesis of compounds 1, 2 and 3. Reagents and conditions: (a) ethanol, 50 ${ }^{\circ}$, 5h; (b) DDQ, $\mathrm{CH}_{2} \mathrm{Cl}_{2}$, rt, 14h; (c) piperidine, ethanol, reflux, 14h, Yield $\mathrm{R}=\mathrm{H} 85 \%$, R=OMe $60 \%$; (d) $\mathrm{BBr}_{3}, \mathrm{CH}_{2} \mathrm{Cl}_{2}, 48^{\circ} \mathrm{C}$, $14 \mathrm{~h}$, Yield $20 \%$.

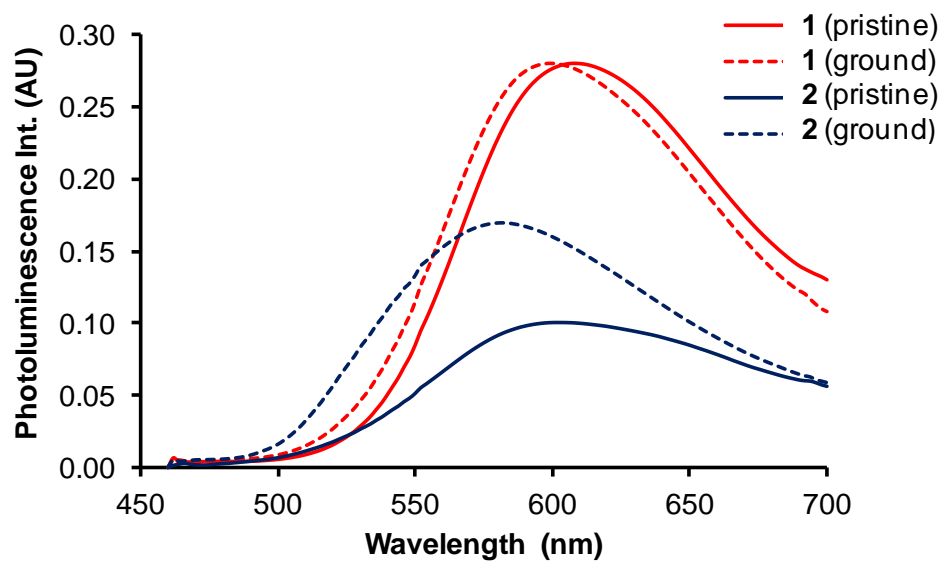

Figure S2. Effect of grinding upon the photoluminescence (PL) spectra of $\mathbf{1}$ and $\mathbf{2}$. The intensity is proportional to PL quantum yield. $\lambda_{\mathrm{ex}}=440 \mathrm{~nm}$. 